\title{
When RateMyProfessor Meets the \#MeToo Movement: Bottom-up Bullying in Academia
}

\author{
Ruth McKay ${ }^{1}$, Bill Irwin ${ }^{2}$, Randy Appel ${ }^{3}$ \\ ${ }^{1}$ Carleton University, Canada \\ ${ }^{2}$ Huron University College, Canada \\ ${ }^{3}$ Waseda University, Japan
}

\begin{abstract}
The \#MeToo and Time's Up movements have created increased awareness around inappropriate work behaviour. According to these two partially overlapping movements, some organizations have been permissive in enabling employees to misuse their positions to assert undue power over others. Managers also recognize that complaint processes may be inadequate in resolving these issues. This paper uses a \#MeToo lens to investigate student bullying, mobbing, and sexual harassment enabled through RateMyProfessor.com (RMP). For this research $R M P$ is used as a proxy for social media sites that are visible and curtained to public viewing. It also considers how the need for the academy to operate as a hyper-commercialized business may be contributing to the silence of universities on the misuse of sites such as RMP. Main research questions include the following. Why is harassment of faculty through social media sites such as RMP permitted and even valued? How do social media sites' content and audience differ from university evaluations of faculty?
\end{abstract}

\section{Introduction}

Universities are reviewing and revising behavioural guidelines and policies to create environments less conducive to bullying and other forms of harassment, but what happens when employees are impacted by a third party, such as RMP, in which institutions of higher education have no control? Keim and McDermott [9] note that within the academy, bullying can occur between students and faculty, with students able to play the role of perpetrator as well as victim. Students engaging in inappropriate behaviour through social media are the major focus of this paper. The questions are, do comments on social media classify as harassment? What is driving it? Why do institutions appear to remain quiet about inappropriate comments concerning faculty visible through social media?

In today's work environment, influenced by the \#MeToo and the Time's Up movements, we should reexamine the impact hurtful comments posted on RMP may have on academics. RMP is a contributor to a perfect storm: the confluence of bottom-up bullying, sexual harassment, academic consumerism, and the freedom/anonymity of on-line social media. This paper examines how the combination of these elements can lead to a problem for academic professionals. We also compare feedback on social media to that of more standardized course evaluations used as part of normal university procedures.

Initially introduced by social activist Tarana Burke in 2006 as a way of offering support to women from marginalized communities who have been victims of sexual assault and harassment [17], the \#MeToo began to gain momentum when celebrities encouraged the use of this hashtag on social media platforms, such as twitter and Facebook, as a way of bringing greater attention to wider issues regarding the prevalence of sexual misconduct women often face in the workplace.

The Time's Up movement is a more formal organization resulting from celebrity efforts to move beyond the 'naming and shaming' of perpetrators of sexual misconduct in order to create greater societal change. Both movements have grown from their initial foci to address a greater variety of issues, methods of remedying the situation, and ways of helping victims. The popularity of the \#MeToo and Time's Up movements have also had a wide-ranging societal impact with tens of thousands of retweets on twitter and a significant increase in web searches related to sexual harassment as a result of the increasing attention brought about by these movements [2].

Since the initial viral spread of these social justice efforts via social media platforms, the focus has continued to expand to include an ever-wider range of topics, and these movements should no longer be viewed as being reserved to issues faced by a single gender or in a particular environment. Furthermore, as a grassroots campaign without an overarching source of control or guidance, the \#MeToo movement continues to shift and adapt to the needs of the communities in which it is adopted. Under this expanded view of the \#MeToo and Times's Up movements, we use the critical lens provided by these campaigns as a way of analyzing the treatment of academic professionals as revealed 
by comments posted on social media by students, with the goal of highlighting the pressures faced by academic professionals as well as the unprofessional and potentially bullying nature of the discourse to which they are subjected.

\section{Change and the Academy}

A key issue in this discussion on how to deal with the "perfect storm" universities are currently facing is how these large traditional institutions deal with change. We argue that given the convalesce of all these factors occurring at the same time, including the rush of external forces beating on the gates of the academy, that change is occurring at a revolutionary pace. Yet from our vantage point, institutions are displaying a slower, evolutionary pattern response to what is happening. Evolution is organic, it takes more time and it is likely the way the university perceives how change as evidenced by the way they engage in change. After all, institutional change is akin to turning an ocean liner. It takes a long time, even if the iceberg is seen ahead, the probability is that you will hit it. As a result of their perspective (large organizations change slowly) they are not adapting fast enough and faculty are being harmed because of it.

Lewin's theory of organizational change best describes how traditional institutional change can occur. Lewin described the traditional model of change as a three-step process. Unfreezing the status quo, making change, and then refreezing the organization with the change incorporated. In their review of organizational change Sundarasaradula et al. [20] note "the merit of a traditional change model lies in its capacity to describe and explain adaptive, gradual and incremental organizational change. This type of change is believed to be typical before the 1970s, when the general environment was relatively simple and static". As Burnes [1] states, "[while] Lewin saw behavioural change as a slow process; however, he did recognize that under certain circumstances, such as a personal, organizational or societal crisis, the various forces in the field can shift quickly and radically".

Our thesis is that revolutionary forces are at play through changes driven by institutional budgetary need for students, rising student notions of consumerism regarding their place in the academy, and unfettered and unchecked use of social media in this environment. The change as we see it is revolutionary - rapid and you need to be part of it or change will happen and you will be stuck with the results. That revolution is what we talk about in this paper. A pivotal issue of this revolution that is occurring is how it appears to normalize and institutionalize upward bullying of faculty.

\section{Sexual Harassment in the Workplace}

Bullying involves an aggressor who perpetrates inappropriate behavior that detrimentally impacts one or more targets. The related term, mobbing, focuses on targets who, according to Einarsen, Hoel, Zapf, and Cooper [4] "are systemically exposed to harassment by one or more perpetrators and who may over time become severely victimized by this treatment". Furthermore, sexual harassment in the work environment has been defined by Lublin [10] as "unwelcome conduct of a sexual nature that detrimentally affects the work environment or leads to adverse job-related consequences for the victims of the harassment... sexual harassment in the workplace attacks the dignity and self-respect of the victim both as an employee and as a human being". Acts of sexual harassment can start with small comments directed to one-person, shared gossip creating a toxic work environment, or more egregious pathways involving a single hostile event. This is true of bullying and mobbing as well. Although single hostile events are very concerning, when inappropriate behaviours become systemic and ignored, or even tolerated, a culture that accepts these forms of harassment can result.

Since the \#MeToo movement began, Lublin [10] has noted that "there has been a seismic shift in how the public views sexual harassment such that complainants are viewed far more credibly than ever before". For organizations, to avoid liability, as well as protect employees and the organization's reputation, this means greater attention should be given to behaviours and comments by employees and customers in order to avoid creating a culture where harassment is allowed to grow. At the postsecondary level these efforts must comprise all key stakeholder groups, including students.

Before the \#MeToo movement, rating professors on attractiveness could be viewed as edgy or fun, and RMP even listed the winners on their hotness measure, the hot chili pepper, at the end of each school year. The popularity of this ranking became both an accolade and an embarrassment, as illustrated by Schwyzer [16], author and former Pasadena City College faculty member: "Judging from my evaluations and "rate my professor" reviews and other remarks, I acknowledge that for whatever reason, I am often regarded as a "hot" professor. I'm not suggesting that I am 
magnificently handsome, just that I tend to get more such responses than many of my colleagues." According to our review of RMP comments for business faculty at the university of $\mathrm{X}$ in the department of Y. Comments on faculty, particularly those rated poorly, included more personal than professional comments. Remarks ranged from informative (e.g., "hard marker") to hostile and personal (e.g., "worst professor ever").

Although more work needs to be done in this area to create a fuller understanding of the issue, previous research has also clearly revealed factors outside those typically associated with professional capability and competence that have a significant impact on student evaluations. In addition to demonstrating a focus on personal as opposed to professional conduct, these comments may be viewed as a representation of gendered discrimination. For example, in a corpus analysis of student comments found on RMP, Subtirelu [19] found that, when compared to female instructors, men were more frequently associated with positive statements related to their level of intelligence and use of humour. As a result, it could be said that male instructors who provide an entertaining in-class experience are favoured by students and that personal conduct may be more important in student evaluations than professional capability when evaluating academic professionals.

In contrast, female instructors were more frequently discussed in terms of their personal demeanor, with critical comments often related to student views of these teachers as 'uncaring'. Alternatively, positive evaluations of female teachers were more often related to assessment of instructors as 'sweet', something not seen among comments for male instructors. These gendered findings may also contribute to previous reports from this same study that female international teaching assistants in higher education find it difficult to gain respect and acceptance from the students they teach. In other words, these efforts to gain acceptance could be made more challenging by the fact that their vocational capabilities as academic professionals maybe downplayed by students in favour of a greater focus on personal characteristics, attitude, and the level of entertainment they provide during class.

\section{RMP and the 'Chili Pepper'}

Prior to June 2018, participants on RMP could ascribe a chili pepper to instructors they felt were "hot". With no criteria provided, it was left up to the opinion of the posting to determine the criteria. The quiet removal of this measure can be described as when RMP met the \#MeToo movement.

If there is any doubt about how inappropriate the hot chili pepper measure was, one need only consider the case of Ross Levinsohn, who in 2017 was named publisher and CEO of the Los Angeles Times. Previously holding various executive positions, he was also an important member of several organizations, such as the Board of Trustees for American University. In 2018, Levinsohn became entangled in controversy due to previous questionable acts he engaged in. Folkenflik [6] states that "Levinsohn has been described as a "fratboy executive" creating discriminatory corporate cultures. One allegation claimed "Levinsohn was sued in separate sexual harassment lawsuits as an executive at two different corporations. By his own sworn testimony, Levinsohn admitted to rating the relative 'hotness' of his female colleagues in office banter as a vice president at a digital media company" [6]. In January 2018, one day after National Public Radio released an article about his past indiscretions, Levinsohn was "placed on an unpaid leave of absence" [7]. While rating hotness is no longer seen as an acceptable metric, this does not mean sexual harassment has abated or that gender views of instructors do not persist. For example, although preliminary, our analysis of RMP comments of business faculty revealed that female professors were more often referred to with gendered pronouns (e.g., "she" and "her") while pronouns denoting gender were used much less frequently for their male colleagues. This suggests that students view female faculty from a more gendered perspective when compared to males. Since, in society at large, women tend to be more frequently judged based on appearance, it remains to be seen if a similar cross over may be witnessed in the comments given to male and female academic professionals. We have yet to develop this research further, but these initial results suggest that there is a continued focus on gender that could potentially point to the presence of sexism and sexual harassment in the academy by way of publicly posted comments and we believe the public nature of these comments causes an additional level of concern.

\section{Bottom-Up Bullying}

Workplace harassment is largely rooted in power differentials, with those in positions of authority misusing their power. However, the rise of social networking sites can shift the balance of power in a manner that may facilitate mobbing. Bottom up, or upward, bullying is classified as actions by a 
subordinate that challenge, embarrass, or undermine an individual in a position of authority. One may assume that professors, due to their responsibility to manage classes and grade students, have power over pupils such that they would be the ones more likely to harass and bully. However, when many students participate in online evaluations, such as those given through RMP, it can lead to a form of mobbing that diminishes and devalues individuals and faculty authority. Mobbing can quickly shift the power from the professor to students, with disturbing results, including disruption, denigration, and even unreasonable or inappropriate demands of professors, all of which can have a serious mental toll on professors.

In all forms of bullying, these actions are undertaken with a goal in mind. With RMP, students use the site to share relevant information on professor's teaching style and grading, but evidence from Felton, Koper, Mitchell, and Stinson [5] indicates it is also used to influence and retaliate against professors. This prevalence of personal attacks is also evident in our preliminary analysis of RMP comments. Furthermore, the anonymity associated with RMP may encourage students to act differently and more harshly than they would in the real world. According to Guedj, Associate Director of the Faculty and Staff Assistance Office of Boston University, "Online harassment cases have been spiking, in particular through Rate My Professor" [3]. Guedj notes that, due to the anonymity of the online medium, the aggressors are hard to identify. This is because virtually anyone can post comments on-line, including current and former students, as well as those who may never have enrolled in a class with the instructor and are simply bitter due to some personal event. As a result, RMP can be viewed as a vehicle for public shaming of professors, regardless of the existence of an actual basis for the comments being posted.

\section{RMP Literature}

Although still a relatively new topic, there is a growing body of research into the use and impact of RMP and other social media sites on the academy and faculty. For example, Felton et al. [5], used an evaluation of overall professor quality ratings in RMP to reveal that these scores were predominately a function of easiness and hotness ratings, with little relationship to student learning. Furthermore, they identified the ratings on RMP as being impacted by a halo effect.

This is relevant because, as Murray and Zdravkovic [11] note, sources in the USA, such as Forbes Magazine, utilize RMP instructor scores to calculate annual rankings of the nation's best postsecondary institutions. In fact, RMP scores comprise twenty-five percent of each school's final grade. Equally concerning, investigations have revealed that "college administrators 'unofficially" use these ratings to evaluate faculty members [12], and that faculty search committees 'unofficially' use them to help determine the quality of job candidates". RMP itself aids in this process by reporting lists of the highest rated professors and top schools/universities, all built on RMP's rating data and anonymously posted comments. Currently, more than 19 million raters are reported to have participated in these ratings, evaluating a total of 1.7 million instructors [13]. As the academy appears to adopt an ever-increasing consumerist perspective, is this practice of using RMP ratings a marketing tool, or are post-secondary organizations unintentionally institutionalizing upward bullying and mobbing?

An encouraging approach to how universities can deal with the problem of online bullying or mobbing can be found at Boston University. Faculty who believe they are victims of cyberbullying are encouraged to act quickly and inform their department chair of any inappropriate behaviours which may constitute bullying. Guedj, Associate Director of the Faculty and Staff Assistance Office, would "like to see campuses offer a fully coordinated institutional response with a formal investigative structure" in cases of cyberbullying aimed at faculty or employees [3]. This is a positive step that can help avoid emotional trauma due to mobbing. However, more needs to be done if the goal is to safeguard faculty and the veracity and integrity of academic institutions. Policy and decision makers at universities also need to acknowledge the lower maturity level and emotional intelligence of some students behind the RMP comments. Furthermore, there needs to be an understanding that the audience for RMP tends to be other students rather than Forbes or search committees, so using RMP comments for employment decisions is akin to listening to students talking to each other as they walk through the university halls and using that unabridged unfiltered data to make employment decisions (see Table 1). Clearly hiring, promotion, and tenure decisions should not be made based on comments or rankings on RMP. However, the issue goes deeper into the mental health of faculty.

Some of the commentary is belittling or denigrating, and bullying comments shared in a forum that can be viewed by virtually anyone should be considered as an instrument for mobbing that must be dealt with. 
Table 1. RMP and University evaluations

\begin{tabular}{|c|c|c|c|c|}
\hline Category & Target Audience & Desired Impact & $\begin{array}{l}\text { Unofficial } \\
\text { Audience }\end{array}$ & $\begin{array}{l}\text { Impact of Unofficial } \\
\text { Use }\end{array}$ \\
\hline $\begin{array}{l}\text { University } \\
\text { Evaluations }\end{array}$ & $\begin{array}{ll}\text { - } & \text { Faculty } \\
\text { - } & \text { Hiring } \\
& \text { committees } \\
\text { - } & \text { University } \\
& \text { administrators } \\
\end{array}$ & $\begin{array}{l}\text { Improve faculty } \\
\text { teaching and use } \\
\text { results for teaching } \\
\text { opportunities and } \\
\text { hiring } \\
\end{array}$ & - $\quad \mathrm{N} / \mathrm{A}$ & - $\quad \mathrm{N} / \mathrm{A}$ \\
\hline $\begin{array}{l}\text { Rate My } \\
\text { Professor }\end{array}$ & - $\quad$ Students & $\begin{array}{l}\text { Aid students to be } \\
\text { informed about the } \\
\text { quality of the } \\
\text { professor's teaching } \\
\text { and the nature and } \\
\text { quantity of the } \\
\text { course work }\end{array}$ & $\begin{array}{ll}\text { - } & \text { General public } \\
\text { - } & \text { Hiring } \\
\text { committees } \\
\text { - } & \text { Academic } \\
& \text { faculty } \\
\text { - } & \text { External } \\
& \text { university } \\
& \text { /faculty rankings }\end{array}$ & $\begin{array}{l}\text { - Opens faculty to } \\
\text { unprofessional } \\
\text { comments of a } \\
\text { personal nature } \\
\text { Can lead to upward } \\
\text { bullying and } \\
\text { mobbing } \\
\text { - Potential to } \\
\text { influence mental } \\
\text { health of faculty } \\
\text { May lead to } \\
\text { changes in course } \\
\text { design /workload } \\
\text { Impacts promotion } \\
\text { and hiring of } \\
\text { faculty }\end{array}$ \\
\hline
\end{tabular}

\section{The Culture of Silence}

Increasingly, university management, faculty, and staff refer to students as customers - suggesting an increasingly commercialized view of academia. As universities fight to maintain enrolment and manage funding, there is increased pressure to ensure there are enough "bums in seats" to guarantee viability. In previous generations, this shift to consumerist nomenclature would have induced debates about the suitability of this perspective, today it is simply accepted. Sax [15] explains in his research on the commercialization of postsecondary education that some students have a limited understanding of academic integrity and often come to class expecting to be entertained. Implicitly, at least, it appears that many faculty members have bought into this conceptual shift, as demonstrated in the phenomena of grade inflation [15] and have bought into the commercialization of academia to survive.

The results of Sax's [15] study indicate that professors who make personal connections with students are favoured. In a system where students can select their professors like products online (with reviews to help narrow down their search), and where that decision is mostly based on the judgments shared by their peers, the consumerist model of university education is reinforced. Ritter
[14] writes, "Students are making educational choices not just on traditional notions of prestige but also on personal notions of 'fit,' construed typically as access - socially and structurally defined - and convenience". Emphasis on these notions of personal fit further reinforce the gradual movement away from the traditional focus of higher education as a place of academic advancement toward a more product-based endeavor, where an entertaining experience, good grades, and a degree are the items being purchased. In light of the increasingly widespread view of academia in consumerist terms, many faculty members seem to have assented to their new role in an effort to appease their students and ensure favourable online reviews.

With some post-secondary institutions using student evaluations to help determine promotion, reappointment, salary increases, and tenure, the submission by academic professionals to the consumerist culture is all the more understandable. Furthermore, with research demonstrating that the content of the course, and 'tough' grading, can adversely impact student ratings of teacher performance [8], many faculty appear to adopt a form of grade inflation and reduce course workload to ensure their evaluations are not negatively impacted by the content they teach. This practice is an 'open secret' in many institutions, where a form of a 'don't ask - don't tell' prevails. It seems that 
there is an unspoken acknowledgement by administrators that if the school appears 'too tough' students will vote with their feet (and their dollars) and go elsewhere. Thus, there appears to be a sense of need to appeal on a consumer level to students for academic institutions to remain viable.

\section{RMP as a Medium for Cyber-Bullying and Mobbing}

When it occurs in technologically mediated forms, the use of repetition as a criterion for bullying becomes a problem. In fact, due to the permanency of online postings, a single act of cyber-bullying through RMP or other social media site may repeat itself without further contribution of the bully, thereby subjecting the victim to consistent and repeated attacks. For example, if insulting content is uploaded onto RMP, or any other publicly accessible forum, every hit on that page could be considered a separate occurrence. In such situations, a teacher's experience would be that they are the target of recurrent bullying that occurs on a near constant basis.

The comments go beyond a professional focus that would include, for example, discussing features of a course. See Table 2 for sample RMP comments for six faculty that would qualify as bullying. Comments such as "She's ridiculous," "Simply an atrocious professor" and "TERRIBLE TERRIBLE professor" do not impart professional specific information but rather suggest there is something wrong with the academic such as having no skills or qualifications to teach.

With on-line bullying, the public nature of the comments and aggression may lead to greater psychological impact for the victim since they are often all too aware that the comments are accessible by anyone inside and outside the institution at which they work. Additionally, since these ratings are often 'unofficially' used to evaluate job candidates, academic professionals targeted in these comments may feel unable to escape their impact.

Table 2. Sample comments on RMP

\begin{tabular}{|c|c|c|}
\hline Professor & $\begin{array}{c}\text { Comment } \\
\text { Examples } \\
\text { Student 1 }\end{array}$ & $\begin{array}{l}\text { Comment } \\
\text { Examples } \\
\text { Student 1 }\end{array}$ \\
\hline A & $\begin{array}{c}\text { Arrogant, } \\
\text { Petty, Talks } \\
\text { about random } \\
\text { things }\end{array}$ & $\begin{array}{c}\text { Miserable } \\
\text { Professor }\end{array}$ \\
\hline
\end{tabular}

\begin{tabular}{|c|c|c|}
\hline B & $\begin{array}{c}\text { Horrendous } \\
\text { experience }\end{array}$ & Brutal \\
\hline C & $\begin{array}{c}\text { Worst prof I } \\
\text { have ever met }\end{array}$ & She's ridiculous \\
\hline D & $\begin{array}{c}\text { TERRIBLE } \\
\text { TERRIBLE } \\
\text { professor }\end{array}$ & $\begin{array}{c}\text { Simply an } \\
\text { atrocious } \\
\text { professor }\end{array}$ \\
\hline E & $\begin{array}{c}\text { Awful, avoid } \\
\text { where } \\
\text { possible }\end{array}$ & Horrible \\
\hline F & $\begin{array}{c}\text { Worst prof I } \\
\text { have had at } \\
\text { XXX }\end{array}$ & Awful prof \\
& \multicolumn{2}{|c}{} \\
\hline
\end{tabular}

Mobbing has been known to occur in a range of workplace environments. Some characteristics of an environment conducive to this behaviour, are the following: "Management generally ignores or misinterprets this type of problem; the workplace does not distinguish mobbing from other forms of harassment; and, after seemingly endless mobbing, victims have no recourse except to give up" [9]. Mobbing can be seen, by definition, as a form of institutionally sanctioned harassment. Perhaps it can even be described as a nuanced form of behavioural modification - behave a certain way, accept a certain practice, or you will be "expelled" from the group and targeted. As it relates to the consumerist turn in academia, the form of mobbing facilitated through RMP can be viewed as a way of ensuring professors adhere to the new ground rules of their profession: provide students with high grades and an entertaining experience or suffer the consequences. This should be extremely concerning not only to academic professionals, but society at large, as the implied goal of bettered communities made possible through the development of citizens with improved knowledge and abilities by way of post-secondary education may be sacrificed in favour of a path that focuses simply on pleasing the 'customers' that choose to enrol at each institution.

In other words, by focusing on easy courses and entertaining experiences to ensure positive student evaluations, the desirable outcome of having more knowledgeable and capable graduates may gradually be lost. Furthermore, by allowing bullying comments about academic professionals to be publicly posted, young academics pursuing a career in the academy may begin to choose alternative paths to avoid the potential for this type of harassment. Thus, the issues brought up in this paper regarding radical change and a perfect storm, as well as the larger issues of harassment and bullying of academics, must be given greater attention. 


\section{Conclusion}

Faced with bottom-up bullying, mobbing and sexual harassment facilitated through anonymous posting on social media sites like RMP and the confluence of academic consumerism and funding pressures, universities need to be proactive to protect faculty and the academic model of education. The issue is most pressing for the courses and faculty that are targeted by students through RMP. The academy can no longer play the role of the silent bystander while academics are bullied and subjected to a toxic work environment initiated and propagated by a third party outside the realm of control or influence of the academy. It is time to name this elephant in the room.

In the \#MeToo environment the bystander is culpable especially if they are the target's employer. What steps can universities take to better manage this issue? Recent attention given to the \#MeToo movement has helped place greater focus on bullying and sexual impropriety in the workplace and provided an insightful lens with which to investigate the current state of academia as it relates to the increasing presence of on-line social commentary of faculty. However, the \#MeToo movement has been more focused on bullying (one aggressor and one or more targets) than mobbing (one target and multiple aggressors). The academy must take a stronger stand on this issue for the mental health of its faculty and the integrity of the institution.

Perhaps part of the answer can be seen in how post-secondary institutions dealt with the COVID 19 crisis? Moving whole institutions and all their functions online appears to energize the scrutiny and associated degree of seriousness that these bodies gave to the online medium. Administrations appear to have had a series of epiphanic moments relating to online teaching environments such as Zoom, Google classroom, Microsoft teams, Blackboard and so forth. At Western University in London Ontario, for example, where Zoom became the dominant online teaching tool in March 2020, administration quickly instituted a series of student restraints, such as universally disabling the chat function between session participants, as a means of maintaining classroom decorum. Student online codes of conduct are now ubiquitous for the virtual classroom environment. Time will tell if these standards become normalized and migrate to the broader arena of student-faculty interaction. However, these steps to facilitate online teaching do not address the core issues around the mobbing medium that RMP and other social media platforms provide for students and the confluence of pressures in the perfect storm of the academy and the inaction that results.

\section{References}

[1] Burnes, B. (2004) "Kurt Lewin and the Planned Approach to Change: A Re-appraisal”, Journal of Management Studies 41:6 September 2004 (p. 982).

[2] Caputi, T., Nobles, A., and Ayers, J.

(2018). Internet searches for sexual harassment and assault, reporting, and training since the \#MeToo movement. JAMA Internal Medicine, 179, 258-259.

[3] Daniloff, C. (2009). Cyberbullying goes to college. Bostonia, The Alumni Magazine of Boston University, Spring 2009 Edition. Retrieved from https://www.bu.edu/bostonia/spring09/bully/ (Access Date: 15 January 2020).

[4] Einarsen, S., Hoel, H., Zapf, D., and Cooper, C. L. (2011). Bullying and harassment in the workplace: Developments in theory, research, and practice. CRC Press: Boca Raton, FL.

[5] Felton, J., Koper, P. T., Mitchell, J., and Stinson, M. (2008). Attractiveness, easiness and other issues: Student evaluations of professors on ratemyprofessors. com. Assessment \& Evaluation in Higher Education, 33(1), 45-61.

[6] Folkenflik, D. (2018, Jan. 18). Accusations Of 'Frat House' Behavior Trail 'LA Times' Publisher's Career. National Public Radio Inc. Retrieved from https://www.npr.org/2018/01/18/578612534/accusationsof-frat-house-behavior-trail-la-times-publisher-s-career (Access Date: 5 January 2020).

[7] James, M. (2018, Jan. 19). L.A. Times Publisher Ross Levinsohn to take unpaid leave of absence. Los Angeles Times. Retrieved from http://www.latimes.com/business/hollywood/la-fi-ctross-levinsohn-leave-20180119-story.html (Access Date: 20 December 2019).

[8] Keashly, L. and Neuman. J. (2010). Faculty experiences with bullying in higher education. Administrative Theory \& Praxis, 32(1), 48-70.

[9] Keim, J. and McDermott, J. (2010). Mobbing: Workplace violence in the academy. The Educational Forum, 74, 167-173.

[10] Lublin, D. (2017, Nov. 30). What counts as sexual harassment in Canada? The Globe and Mail. Retrieved from https://www.theglobeandmail.com/report-on-busi ness/careers/leadership-lab/what-counts-as-workplacesexual-harassment-in-canada/article37137194, (Access Date: 5 January 2020). 
[11] Murray, K., and Zdraokovic, S. (2016). Does MTV really do a good job of evaluating professors? An empirical test of the internet site RateMyProfessor.Com. Journal of Education for Business, 91(3), 138-147.

[12] Pannapacker, W. A. (2007). The inescapability of your past. The Chronicle of Higher Education, 53 (33), B11.

[13] RateMyProfessor (2020). Rate My Professor. Retrieved July 12, 2018, from https://www.google.ca/search?q=rate+my+professor\&oq $=$ Rate \&aqs $=$ chrome.1.69i57j0j69i59j69i6013.3718j0j7\&s ourceid=chrome\&ie=UTF-8 (Access Date: 10 January 2020).

[14] Ritter, K. (2008). E-Valuating learning: Rate my professors and public rhetorics of pedagogy. Rhetoric Review, 27(3), 259-280.

[15] Sax, B. (2004). Students as customers. On the Horizon, 12(24), 157-159.

[16] Schwyzer, H. (2005, Feb. 25). The male teacher's body and propriety. [Author's Blog]. Retrieved from http://hugoboy.typepad.com/hugo_schwyzer/2005/02/my _post_below_o.html (Access Date: 7 December 2019).

[17] Shugerman, E. (2017). Me too: Why are women sharing stories of sexual assault and how did it start? The Independent. Retrieved from https://www.independent. co.uk/news/world/americas/me-too-facebook-hashtagwhy-when-meaning-sexual-harassment-rape-storiesexplained-a8005936.html (Access Date: 5 January 2020).

[18] Stroebe, W. (2016). Why good teaching evaluations may reward bad teaching: On grade inflation and other unintended consequences of student evaluations.

Perspectives on Psychological Science, 11(6), 800-816.

[19] Subtirelu, N. C. (2015). " She does have an accent but...": Race and language ideology in students' evaluations of mathematics instructors on RateMyProfessors. com. Language in Society, 35-62.

[20] Sundarasaradula, D., Hasan, H., Walker, D. S., and Tobias, A. M. (2005). Self-organization, evolutionary and revolutionary change in organizations. Strategic Change, 14(7), 367-380. 